\title{
The major approaches to prasugrel and ticagrelor in patients with acute coronary syndrome: State of the art
}

Maria Christiane Valéria Braga Braile-Sternieri ${ }^{1}$, Victor Rodrigues Ribeiro Ferreira ${ }^{1,2}$, Eliana Migliorini Mustafa ${ }^{1}$, Sofia Braile Sabino ${ }^{1}$, Giovanni Braile Sternieri' ${ }^{1}$, Luiza Braile Verdi ${ }^{1}$, Cibele Olegário Vianna Queiroz ${ }^{1}$, Bethina Canaroli Sbardellini ${ }^{1}$, Idiberto José Zotarelli Filho, ${ }^{1,2}$, Domingo Marcolino Braile ${ }^{1}$

${ }^{1}$ Domingo Braile Institute of Sao Jose do Rio Preto (SP), Rua Luiz Vaz de Camoes, 3111 - Vila Redentora, São José do Rio Preto-SP, 15015-750, Brazil ${ }^{2}$ Faceres - Medical School of Sao Jose do Rio Preto, Av. Anisio Haddad, 6751-Jardim Francisco Fernandes, São José do Rio Preto - SP, 15090-305, Brazil

\section{Short Communication}

In the setting of the Acute Coronary Syndrome (ACS), Aspirin is recommended for all suspected patients, unless contraindicated. The addition of a second antiplatelet agent such as Clopidogrel, Ticagrelor or Prasugrel is also recommended for most patients. Parenteral anticoagulation is recommended with unfractionated heparin, low molecular weight heparin, Bivalirudin and Fondaparinux [1]. Proton pump inhibitors are recommended to prevent bleeding due to the use of antiplatelet agents and anticoagulation in patients with an aboveaverage risk of gastrointestinal bleeding. Other medical therapies should include statins, angiotensin-converting enzyme inhibitors, betablockers, nitroglycerin and morphine, and oxygen. For patients with ST-segment elevation myocardial infarction, percutaneous coronary intervention (PCI) with stent placement should be performed as soon as possible. However, fibrinolytic therapy should be used first if the PCI takes longer than 120 minutes.

For ACS without ST-segment elevation, PCI is recommended. Fibrinolytic therapy is usually not recommended. If patients require a coronary artery bypass graft to restore coronary artery flow, the ideal is to postpone 3 to 7 days after admission, unless the patient has cardiogenic shock, life-threatening arrhythmias, three-vessel disease (with occlusion $70 \%$ each), greater than $50 \%$ left coronary artery occlusion, unsuccessful or complicated PCI or mechanical complications (for example, valve rupture) [1].

In this context, Prasugrel and Ticagrelor are emerging antiplatelet drugs that may have the potential to replace the antiplatelet agents currently used. Previous analyzes comparing Prasugrel with Ticagrelor have focused on an indirect comparison, while the direct comparison has been reported only in a few recently published studies. Thus, in 2017, a meta-analysis study of randomized studies systematically performed a direct comparison of adverse clinical outcomes associated with Prasugrel versus Ticagrelor in patients with ACS [2]. Four studies were included with a total number of 563 patients (2012-2016) $(282$ patients were treated with Prasugrel and 281 patients were treated with Ticagrelor). The results of this analysis showed no significant difference in mortality between Prasugrel and Ticagrelor with OR: 1.52, 95\% CI: $0.42-5.45 ; \mathrm{p}=0.52$. In addition, myocardial infarction, major adverse cardiac events, stroke and stent thrombosis were also not significantly different with OR: $0.59,95 \%$ CI: $0.08-4.58$; $p=0.62$, OR: $0.91,95 \% \mathrm{CI}$ : 0.37-2.21; $\mathrm{p}=0.83$, OR: $0.60,95 \%$ CI: $0.08-4.58$; $\mathrm{p}=0.62$ and OR: 0.59 , 95\% CI: $0.08-4.58 ; \mathrm{p}=0.62$, respectively. Thrombolysis in myocardial infarction defined minor bleeding and minimal bleeding was also not significantly different between these two newer antiplatelet agents with
OR: 3.11 ; $95 \%$ CI: $0.48-19.94 ; \mathrm{p}=0.23$ and OR: $2.39,95 \%$ CI: $0.35-16.42$; $\mathrm{p}=0.38$, respectively. In addition, the bleeding defined by the academic research consortium also manifested itself in a similar way with OR: 0.92, 95\% CI: 0.39-2.13; $\mathrm{p}=0.84$. In patients with ACS, both Prasugrel and Ticagrelor had similar adverse cardiovascular results and bleeding events. There was no significant difference between these two most recent antiplatelet agents during this direct comparison. However, upcoming trials with long-term follow-up periods may completely resolve this important clinical problem [2].

In this sense, in 2019, in the scenario of the ISAR-REACT 5 study, which was designed to be able to demonstrate the theoretical superiority of Ticagrelor over Prasugrel in patients with the ACS submitted to the invasive strategy, it ended up demonstrating exactly the opposite [3].

Thereby, approximately 4000 patients were randomized to receive Ticagrelor $(n=2012)$ or Prasugrel $(n=2006)$. In patients with STsegment elevation infarction, antiplatelet therapy was administered at randomization. In the case of ACS without ST-segment elevation, patients randomized to the Ticagrelor group received the drug at randomization, while those drawn to the Prasugrel group received the medication at the time of cardiac catheterization, after defining the anatomy, as evidence from previous studies. Approximately $85 \%$ of patients were revascularized by the PCI [3].

The primary endpoint was the combination of AMI, stroke or death and occurred in $9.3 \%$ of patients in the Ticagrelor group versus $6.9 \%$ in the Prasugrel group (RR 1.36, $\mathrm{p}=0.006$ ), after one year. In addition to the unexpected result, the magnitude of the difference was very significant, demonstrating a clear superiority of Prasugrel when compared side by side with Ticagrelor [3].

Regarding secondary outcomes, the occurrence of myocardial infarction stands out, which was lower in patients who received Prasugrel: $3.7 \%$ vs. $4.8 \%$ - RR 1.23 (95\% CI 1.18-2.25). The other secondary outcomes-mortality and stroke alone-had a numerical trend in favor of Prasugrel but did not reach statistical significance. There were also no differences in relation to major bleeding and stent thrombosis. Despite being a very robust study, some limitations were raised after the presentation. Among them, the fact that it is not a blind

${ }^{*}$ Correspondence to: Idiberto José Zotarelli Filho, Domingo Braile Institute of Sao Jose do Rio Preto (SP), Rua Luiz Vaz de Camoes, 3111 - Vila Redentora, São José do Rio Preto-SP, 15015-750, Brazil, E-mail: m.zotarelli@gmail.com

Received: April 10, 2020; Accepted: April 20, 2020; Published: April 27, 2020 
study, the absence of a specific analysis on the adherence of drugs and the different moments of administration of medications stand out [4].

Although complementary studies are suggested to confirm these results, ISAR-REACT 5 has great potential to change the routine in the care of patients with ACS, especially those with ACS without STsegment elevation. In this case, due to the superiority of Prasugrel, the time to administer the drug would be in cardiac catheterization, after defining the anatomy. Most likely, this would have an impact on the time that is expected for the invasive strategy, with a tendency to perform the catheterization earlier, thus avoiding potential damage related to a prolonged time without double antiplatelet therapy [4].

\section{References}

1. Braun M, Kassop D (2020) Acute Coronary Syndrome: Management. FP Essent 490: 20-28. [Crossref]

2. Bundhun PK, Shi JX, Huang F (2017) Head to head comparison of Prasugrel versus Ticagrelor in patients with acute coronary syndrome: a systematic review and metaanalysis of randomized trials. BMC Pharmacol Toxicol 18: 80. [Crossref]

3. Schupke S, Neumann FJ, Menichelli M, Mayer K, Bernlochner I, et al. (2019) Ticagrelor or Prasugrel in Patients with Acute Coronary Syndromes. $N$ Engl J Med 381: 1524-1534. [Crossref]

4. Jneid H (2019) Ticagrelor or Prasugrel in Acute Coronary Syndromes - The Winner Takes It All? N Engl J Med 381: 1582-1585. [Crossref]

Copyright: $(02020$ Braile-Sternieri MCVB. This is an open-access article distributed under the terms of the Creative Commons Attribution License, which permits unrestricted use, distribution, and reproduction in any medium, provided the original author and source are credited. 